\title{
Platelet and coagulation factors in proliferative diabetic retinopathy
}

\author{
DQ BORSEY,* CV PROWSE, † RS GRAY, ${ }^{*}$ J DAWES, $¥$ K JAMES,§ RA ELTON, $\|$ \\ BF CLARKE*
}

From the ${ }^{*}$ Diabetic and Dietetic Department; $†$ Blood Transfusion Service, Royal Infirmary, Edinburgh; $\ddagger M R C$ Immunoassay Team, Edinburgh; §Department of Surgery and \|Medical Computing and Statistics Unit, University of Edinburgh, Scotland

SUMMARY Plasma $\beta$-thromboglobulin, platelet factor 4 , fibrinogen, fibrinopeptide A, antithrombin III, factor VIII related antigen, $\alpha_{2}$-macroglobulin, platelet count, and total glycosylated haemoglobin were measured in three well matched groups of subjects: non-diabetic controls, diabetics without retinopathy, and diabetics with proliferative retinopathy. $\beta$-thromboglobulin and platelet factor 4 concentrations were significantly higher in the diabetics with retinopathy than in the controls and platelet factor 4 was also increased in the diabetics without retinopathy compared with controls. Fibrinogen concentration was raised in diabetics without retinopathy compared with controls, diabetics with retinopathy compared with controls, and diabetics with retinopathy compared with those without. Fibrinopeptide A concentration did not differ significantly between groups. Antithrombin III levels were increased in diabetics with retinopathy compared with controls, and in diabetics with retinopathy compared with those without. Factor VIII related antigen values were higher in both the diabetic groups when compared with the controls. Fibrinopeptide A concentration correlated with both $\beta$-thromboglobulin and platelet factor 4 in each of the three groups.

Haemostatic abnormalities in diabetes have been shown, although a hypercoagulable state has not been confirmed. These changes in platelet and coagulation function may be secondary to the development of microvascular disease and their role in the pathogenesis of retinopathy remains uncertain.

Patients with diabetes mellitus have significantly increased morbidity and mortality as a consequence of specific microvascular disease, which results in conditions such as retinopathy and nephropathy. Although the precise cause of these vascular complications remains uncertain, evidence is accumulating that an imbalance of the haemostatic mechanisms may be entailed in their initiation or propagation. Various abnormalities of platelet function and of coagulation in diabetes have been identified and recently reviewed. ${ }^{1}$ The contradictory findings and conclusions of different research groups may be partially attributed to the heterogeneity of their diabetic patients, the poor matching of control groups, the non-standardisation of coagulation and platelet assays, and the uncertain importance of abnormal in vitro tests.

Accepted for publication 20 February 1984
We have measured plasma concentrations of $\beta$-thromboglobulin, platelet factor 4 , fibrinogen, fibrinopeptide A, antithrombin III, factor VIII related antigen, $\alpha_{2}$-macroglobulin, platelet count, and total glycosylated haemoglobin in three well matched groups of subjects: non-diabetic controls, insulin dependent diabetics without retinopathy, and insulin dependent diabetics with proliferative retinopathy.

\section{Patients and methods}

PATIENTS

We studied 20 healthy non-diabetic controls, 20 insulin dependent diabetics without ophthalmoscopic evidence of retinopathy, and 20 insulin dependent diabetics with proliferative retinopathy. Subjects in each group were individually matched for age, sex and, where applicable, duration of diab- 
Table 1 Details of the subjects studied

\begin{tabular}{|c|c|c|c|}
\hline & \multirow{2}{*}{$\begin{array}{l}\text { Normal } \\
\text { subjects }\end{array}$} & \multicolumn{2}{|l|}{ Diabetics } \\
\hline & & $\begin{array}{l}\text { without } \\
\text { retinopathy }\end{array}$ & $\begin{array}{l}\text { with } \\
\text { retinopathy }\end{array}$ \\
\hline $\begin{array}{l}\text { No of subjects } \\
\text { \% male } \\
\text { Age (yr) } \\
\text { Duration of diabetes (yr) } \\
\text { Daily insulin dose (units) } \\
\text { \% ideal body weight* }\end{array}$ & $\begin{array}{l}20 \\
60 \\
35 \pm 9 \\
- \\
-\end{array}$ & $\begin{array}{l}20 \\
60 \\
34 \pm 9 \\
21 \pm 7 \\
62 \pm 18 \\
101 \pm 11\end{array}$ & $\begin{array}{l}20 \\
60 \\
35 \pm 11 \\
19 \pm 7 \\
68 \pm 29 \\
100 \pm 11\end{array}$ \\
\hline
\end{tabular}

Values given as mean $\pm 1 \mathrm{SD}$.

*Metropolitan Life Assurance Company Tables 1960.

etes. Details of the subjects studied are given in Table 1. All diabetics had presented with the clinical features of type I diabetes before the age of 35 and been treated with insulin since diagnosis.

All subjects had normal serum creatinine concentrations and absence of proteinuria on testing with Albustix. None had chronic liver disease or was receiving drugs (for example, oral contraceptives, salicylates) known to interfere with haemostasis. Only two of the diabetics studied had signs or symptoms, or both, of macrovascular disease (one angina and the other peripheral vascular disease) and they both had retinopathy.

\section{METHODS}

All diabetic fundi were examined ophthalmoscopically through dilated pupils by one observer (BFC). Proliferative retinopathy was defined as the presence of neovascularisation. A single, 2 h postprandial venous blood sample was withdrawn into a polypropylene syringe, with minimal venous stasis, from resting subjects. The samples were analysed as detailed below:

$\beta$-thromboglobulin-radioimmunoassay of samples collected into anticoagulant mixture containing prostaglandin $\mathrm{E}_{1}{ }^{23}$

Platelet factor 4 -radioimmunoassay. ${ }^{4}$

Fibrinopeptide $A$-radioimmunoassay of samples collected into aprotinin-heparin. ${ }^{5}$

Fibrinogen (factor I) - clot turbidity assay of Ellis and Stransky. ${ }^{\circ}$

Antithrombin III

(a) Antithrombin III activity-bioassay with chromogenic substrate using a commercially available kit (Boehringer-Mannheim Ltd).

(b) Antithrombin III antigen-electroimmunoassay method of Laurell using commercial antisera (Behringwerke).

Factor VIII related antigen-electroimmunoassay method of Laurell using commercial antisera (Behringwerke).

$\alpha_{2}$-macroglobulin-standard Mancini gel diffusion method. ${ }^{8}$ Standard antigen in four different concent- rations was included on every plate. The standard was a human $\alpha_{2}$-macroglobulin reference obtained from Meloy Laboratories Inc (Springfield, Virginia, USA). $\alpha_{2}$-macroglobulin was measured only in the diabetic subjects.

Glycosylated haemoglobin-measured by a modification of the short column chromatographic method of Kynoch and Lehmann.'

Platelet count-electronically determined using the Thrombocounter (Coulter Ltd).

The assay methods for $\beta$-thromboglobulin, platelet factor 4 , fibrinopeptide $A$, antithrombin III activity, antithrombin III antigen, and factor VIII related antigen gave within batch coefficients of variation between 4 and $6 \%$ with between batch coefficients of variation of $8-12 \%$. The between batch coefficient of variation for glycosylated haemoglobin was $3.5 \%$. Fibrinogen levels and platelet count were determined by non-batch methods with coefficients of variation of $5 \%$ and $3 \%$ respectively. Previous studies by one of us have shown that the assay procedure for $\alpha_{2-}$ macroglobulin is highly reproducible (100 \pm $2 \cdot 2 \%){ }^{8}$ Further details of the above assays are available in the quoted references.

Laboratory staff were unaware of the identities of the samples.

\section{STATISTICAL METHODS}

Non-parametric methods were used to analyse the data in view of the presence of skew and outliers in at least some of the measurements. Median and range were used as summary statistics within groups, paired measurements were tested between groups by Wilcoxon's signed rank tests, and associations between measurements within groups by Kendall rank correlation coefficients.

\section{Results}

Table 2 details the medians and ranges of the measured platelet and coagulation factors within the three groups and also the results of a comparison of paired measurements between groups.

$\beta$-thromboglobulin concentrations were higher ( $p$ $<0.01$ ) in the diabetics with retinopathy than in the non-diabetic controls, and the platelet factor 4 values were significantly increased in both the diabetic groups when compared with the controls (diabetics with retinopathy $p<0.01$; diabetics without retinopathy $p<0.05$ ). A highly significant correlation between $\beta$-thromboglobulin and platelet factor 4 were seen in each of the three groups (controls and diabetics with retinopathy $p<0.001$; diabetics without retinopathy $\mathrm{p}<0.01$ ).

The fibrinogen concentrations were higher in the 
Table 2 Platelet and coagulation factors (median and range) in the three study groups and a comparison of paired measurements between groups

\begin{tabular}{|c|c|c|c|c|c|c|}
\hline & \multirow{2}{*}{$\begin{array}{l}\text { Non-diabetic } \\
\text { controls }\end{array}$} & \multicolumn{2}{|c|}{ Diabetics } & \multirow{2}{*}{$\begin{array}{l}\text { Controls } v \\
\text { diabetics without } \\
\text { retinopathy }\end{array}$} & \multirow{2}{*}{$\begin{array}{l}\text { Controls } v \\
\text { diabetics with } \\
\text { retinopathy }\end{array}$} & \multirow{2}{*}{$\begin{array}{l}\text { Diabetics with } \\
\text { retinopathy } v \text { those } \\
\text { without }\end{array}$} \\
\hline & & without retinopathy & with retinopathy & & & \\
\hline $\begin{array}{l}\beta \text {-thromboglobulin } \\
\text { (ng/ml) }\end{array}$ & $31 \cdot 5(19 \cdot 1-68 \cdot 5)$ & $44 \cdot 9(22 \cdot 2-96 \cdot 3)$ & $51 \cdot 5(24 \cdot 1-127 \cdot 5)$ & NS & $\dagger$ & NS \\
\hline$(\mathrm{ng} / \mathrm{ml})$ & \multirow{2}{*}{$\begin{array}{c}10.4(10.0-52.0) \\
1.70(1.04-2.93)\end{array}$} & $17 \cdot 5(8 \cdot 5-72 \cdot 6)$ & $19.6(6.7-63.7)$ & $*$ & $\dagger$ & NS \\
\hline $\begin{array}{l}\text { Fibrinogen (g/l) } \\
\text { Fibrinopeptide A }\end{array}$ & & $2.46(1.56-3.46)$ & $2.93(1.85-5.70)$ & $\dagger$ & $\ddagger$ & \\
\hline$(\mathrm{ng} / \mathrm{ml})$ & $1.64(1.60-19.20)$ & $2 \cdot 82(2 \cdot 00-16 \cdot 60)$ & $2 \cdot 80(2 \cdot 00-17 \cdot 80)$ & NS & NS & NS \\
\hline activity (\%) & $103(82-119)$ & $104(92-122)$ & $116(92-132)$ & NS & $\ddagger$ & $\dagger$ \\
\hline $\begin{array}{l}\text { antigen }(\%) \\
\text { Factor VII related }\end{array}$ & $100(76-126)$ & $100(87-121)$ & $113(87-126)$ & NS & * & $*$ \\
\hline $\begin{array}{c}\text { antigen }(\%) \\
\alpha \text { macroglobulin }\end{array}$ & $98(72-140)$ & $252(126-460)$ & $267(142-400)$ & $\ddagger$ & $\ddagger$ & NS \\
\hline$(\mathbf{m g} \%)$ & - & $378(192-641)$ & $480(187-696)$ & - & - & NS \\
\hline$\left(\times 10^{\circ} / 1\right)$ & $226(106-284)$ & $255(104-420)$ & $267(126-350)$ & $*$ & NS & NS \\
\hline $\begin{array}{l}\text { Grycosylated } \\
\text { haemoglobin (\%) }\end{array}$ & $6 \cdot 6(5 \cdot 6-8 \cdot 3)$ & $10.7(8 \cdot 3-14 \cdot 1)$ & $11 \cdot 7(10.2-15 \cdot 9)$ & $\ddagger$ & $\ddagger$ & $*$ \\
\hline
\end{tabular}

NS $=$ not significant.

${ }_{p}^{*}<0.05, f_{p}<0.01, \neq p<0.001$

two diabetic groups than in the controls and also in the diabetics with retinopathy than in those without retinopathy.

There was no significant difference in fibrinopeptide A concentrations between the three groups. Within each group, however, fibrinopeptide A cor-

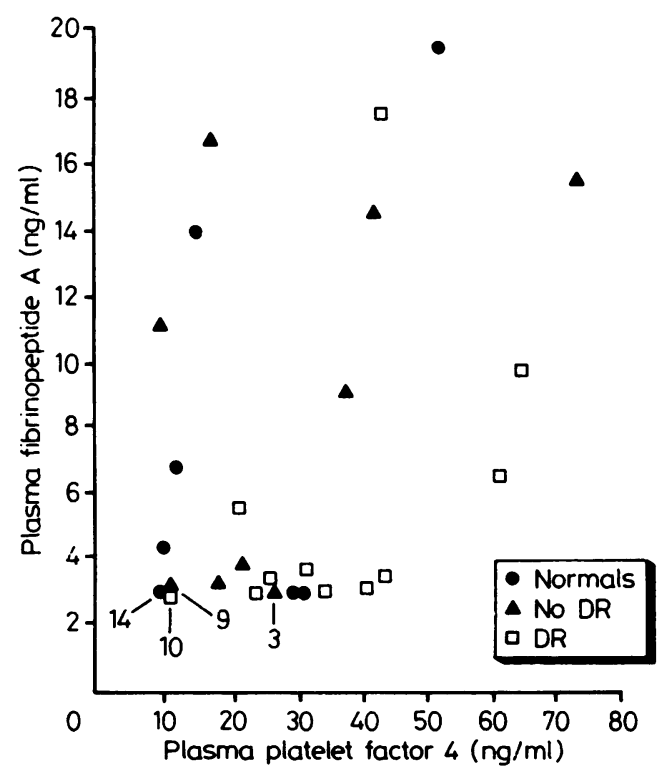

Correlation of platelet factor 4 with fibrinopeptide $A$. Normals: $r=0.45, p<0.05$; no diabetic retinopathy (No $D R): r=0.36, p<0.05$; diabetic retinopathy $(D R): r=$ $0.44, p<0.05$. related significantly with $\beta$-thromboglobulin ( $\mathrm{p}<$ 0.05 ) and platelet factor 4 (controls and diabetics without retinopathy $p<0.05$; diabetics with retinopathy $\mathrm{p}<0.01$ ) (Figure).

Antithrombin III (activity and antigen) levels were significantly higher in the diabetics with retinopathy than in either of the other groups. There was a strong correlation between antithrombin III activity and antigen in each of the three groups (controls $p<0.01$; diabetic groups $p<0.001)$. The concentration of $\alpha_{2}$-macroglobulin was higher in the diabetics with retinopathy, than in those without but this difference was not significant. $\alpha_{2}$-macroglobulin correlated with antithrombin III antigen only in the diabetics with retinopathy. There was no correlation between $\alpha_{2}$-macroglobulin and antithrombin activity.

Concentrations of factor VIII related antigen were higher in both the diabetic groups than in the non-diabetic controls ( $p<0.001)$.

The platelet count was higher in the nonretinopathic diabetics than in the control subjects ( $p$ $<0.05$ ), but no other significant differences existed between groups.

Total glycosylated haemoglobin was higher in the diabetics with retinopathy than in those without ( $p$ $<0.05$ ). The relation between glycosylated haemoglobin and the haemostatic factors studied was considered in each of the three groups: the only significant correlations were with fibrinogen in the control group ( $p<0.001)$, with platelet factor 4 in the uncomplicated diabetics $(p<0.05)$, and with fibrinopeptide $A$ and $\alpha_{2}$-macroglobulin in the diabetics with retinopathy $(\mathrm{p}<0.05)$. 


\section{2}

\section{Discussion}

The published work provides a confusing picture of the importance of haemostatic abnormalities in the development of diabetic retinopathy. The poor matching of study groups, the non-standardisation of assays, the uncertain relevance of in vitro tests to in vivo function, and the inclusion of patients with coincident nephropathy and macroangiopathy have all contributed to this confusion. The subjects in our groups were individually matched for age, sex, and, where applicable, duration of diabetes, and all diabetics with nephropathy were excluded. In contrast to many previous studies, our two diabetic groups were chosen to represent the extremes of the "retinopathy spectrum"-namely, those without retinopathy and those with proliferative retinopathy. Unfortunately, the exclusion of patients with asymptomatic large vessel disease remains a problem since it necessitates unacceptable extensive and invasive investigation.

The platelet specific proteins $\beta$-thromboglobulin and platelet factor 4 are released together from $\alpha$ granules during platelet aggregation, and increased plasma levels may reflect enhanced in vivo platelet activation. Their precise biological functions remain uncertain. $\beta$-thromboglobulin may reduce prostacyclin generation in the vessel wall $^{10}$ and thus allow a more sustained platelet-endothelial interaction. Platelet factor 4 has heparin neutralising activity" and may neutralise any natural heparin like inhibitors of coagulation. It has been suggested that intensive release of platelet factor 4 modifies the surface properties of the platelet membrane and thereby accelerates the rate of formation of the fibrin network between platelets. ${ }^{12} \mathrm{~A}$ close correlation between the plasma levels of platelet factor 4 and $\beta$-thromboglobulin has been well described. ${ }^{413-15}$

Both our diabetic groups had higher $\beta$-thromboglobulin concentrations than the controls, although this was significant only in patients with retinopathy. Both normal ${ }^{1617}$ and increased $^{2518-20}$ plasma $\beta$-thromboglobulin concentrations have been reported in diabetes. The lack of a significant difference in $\beta$-thromboglobulin concentrations between the diabetics with retinopathy and those without is in keeping with a previous report from Edinburgh, ${ }^{2}$ but contrasts with work from other centres. ${ }^{15} 18-21$ The inconsistent findings of previous studies may be partially attributed to the use of different anticoagulant mixtures, sampling techniques, and assay methods ${ }^{2}$ and to the inclusion of diabetics with nephropathy. The latter is important since plasma $\beta$-thromboglobulin (but not platelet factor 4 ) concentrations are increased in the
Borsey, Prowse, Gray, Dawes, James, Elton, Clarke $\stackrel{\varrho}{\overline{\bar{J}}}$

presence of renal impairment. ${ }^{1420}$

The platelet factor 4 results were, as expected, similar to those for $\beta$-thromboglobulin, although both diabetic groups had significantly higher levels $\stackrel{\mathcal{D}}{\stackrel{P}{+}}$ than the non-diabetics. Platelet factor 4 concentration has been previously reported as both normal ${ }^{1722}$ and increased in diabetics. ${ }^{15} 23$

Fibrinopeptide A, which is cleaved from $\stackrel{\mathbb{D}}{D}$ fibrinogen by thrombin, is a sensitive indicator of thrombin formation ${ }^{24}$ and the lack of a significant difference in concentrations between our three groups is evidence against activation of the coagula- $\vec{\omega}$ tion system in diabetes. Our finding that fibrinopeptide A concentrations correlated with both $\beta$-thromboglobulin and platelet factor 4 concentrations suggests that thrombin may initiate the platelet $\sigma$ release reaction. A close association between thrombin formation and the platelet release reaction 6 in normal subjects has been previously noted in 을 vitro $^{25}$ and a correlation between fibrinopeptide $\mathrm{A}-$ and $\beta$-thromboglobulin in diabetics has been reported by Burrows. ${ }^{21}$

Fibrinogen is the immediate precursor of fibrin, influences plasma viscosity, ${ }^{26}$ and is a necessary cofactor for ADP and epinephrine induced platelet aggregation. ${ }^{27}$ It is generally agreed that fibrinogen concentrations are increased in diabetic patients when compared with controls ${ }^{28-30}$ and several authors have, as in our study, shown higher concentrations in diabetics with retinopathy than in those without. ${ }^{29-31}$ This increase in fibrinogen concentration may be non-specific, perhaps in response to chronic vascular injury, rather than reflecting a hypercoagulable state.' The higher concentrations of other acute phase reactants (such as haptoglobin, $\beta$-lipoprotein, and caeruloplasmin) in the serum of diabetic subjects ${ }^{32}$ lends support to this view. Our study has failed to confirm a reported correlation between glycosylated haemoglobin and fibrinogen in diabetics. ${ }^{33}$

Antithrombin III is the major inhibitor of the activated coagulant enzymes XIIa, XIa, IXa, Xa, and thrombin. The risk of thrombo-embolic disease in patients with congenital antithrombin III defi- o $\widetilde{N}$ ciency is significantly increased. ${ }^{34}$ In a hypercoagul- N able state antithrombin III would be consumed and low circulating levels expected. Our findings of raised antithrombin III levels in those diabetics with retinopathy was therefore somewhat surprising. There have been reports of low, ${ }^{35-37}$ normal, ${ }^{38}{ }^{39}$ and $\mathscr{D}$ raised $^{22} 29^{40}$ levels of antithrombin III in diabetes. Discrepancies between functional and immunological assays may account for some of these inconsistencies, although we found a strong correlation between antithrombin III activity and antigen. What then is the explanation of our findings? The raised 
levels of antithrombin III may simply represent part of an acute phase reaction occurring subsequent to the development of retinopathy. Alternatively, an increase in antithrombin III may occur as a defence response to enhanced intravascular production of thrombin via a feedback mechanism increasing synthesis or decreasing catabolism of antithrombin III. ${ }^{41}$

$\alpha_{2}$-macroglobulin is a further inhibitor of coagulation proteases which accounts for about a quarter of the total functional antithrombin III activity in the blood. Indeed, Elder et $a l^{40}$ attributed the raised levels of antithrombin III activity in their diabetics to an increase in $\alpha_{2}$-macroglobulin concentrations. We found no correlation between antithrombin III activity and $\alpha_{2}$-macroglobulin. Although it is generally accepted that $\alpha_{2}$-macroglobulin levels are higher in diabetics, ${ }^{314243}$ the relation between retinopathy and $\alpha_{2}$-macroglobulin has remained uncertain because of other variables including age, duration of diabetes, metabolic control and nephropathy, which may influence $\alpha_{2}$-macroglobulin levels. ${ }^{42-44}$ Previous studies, which often failed to consider these factors, have reported both higher $\alpha_{2}$-macroglobulin concentrations in diabetics with retinopathy ${ }^{31}{ }^{43}$ and comparable levels in retinopaths and non-retinopaths. ${ }^{42}$ Our results are in keeping with those of Gray et al, ${ }^{45}$ who found no significant difference in $\alpha_{2}$-macroglobulin levels between diabetics with retinopathy and those without when all the above variables were taken into account.

Factor VIII related antigen is a glycoprotein, higher oligomers of which are active in promoting platelet adhesion. It is found only in endothelial cells (where it is synthesised), platelets, and megakaryocytes. ${ }^{46}$ Von Willebrand's factor appears to be a property of factor VIII related antigen ${ }^{47}$ and these factors are associated in plasma with factor VIII coagulant activity. Our finding of increased factor VIII related antigen levels in diabetic patients is in keeping with previous reports ${ }^{334849}$ and could result from enzymic degradation in the circulation of the factor VIII polymer and/or from greater endothelial synthesis and release of factor VIII related antigen. ${ }^{5051}$ The lack of raised plasma fibrinopeptide A levels supports the latter explanation since in an enzymatically active environment one would expect increased thrombin formation. We found no significant difference in factor VIII related antigen values between diabetics with retinopathy and those without, although higher levels have been previously reported in diabetics with vascular disease. ${ }^{485052}$

This study has shown certain platelet and coagulation abnormalities in diabetes, but the presence of a hypercoagulable state has not been confirmed. Sev- eral of our findings may be explained on the basis of a non-specific stress reaction in diabetics, possibly secondary to chronic vascular damage. Further studies, particularly of a prospective nature, are clearly indicated to determine whether the observed changes are causal or secondary to the vascular complications of diabetes mellitus.

\section{References}

' Jones RL, Peterson CM. Haematologic alterations in diabetes mellitus. Am J Med 1981;70:339-52.

${ }^{2}$ Borsey DQ, Dawes J, Fraser DM, Prowse CV, Elton RA, Clarke BF. Plasma beta-thromboglobulin in diabetes mellitus. Diabetologia 1980;18:353-7.

${ }^{3}$ Bolton AE, Ludlam CA, Moore S, Pepper DS, Cash JD. Three approaches to the radioimmunoassay of human $\beta$-thromboglobulin. Br J Haematol 1976;33:233-8.

${ }^{4}$ Bolton AE, Ludlam CA, Pepper DS, Moore S, Cash JD. A radioimmunoassay for platelet factor 4. Thromb Res 1976;8:51-8.

${ }^{5}$ Kockum C. Radioimmunoassay of fibrinopeptide A: Clinical applications. Thromb Res 1976;8:225-36.

' Ellis BC, Stransky A. A quick and accurate method for the determination of fibrinogen in plasma. J Lab Clin Med 1961;58:477-88.

' Laurell CB. Quantitative estimation of proteins by electrophoresis in agarose gel containing antibodies. Anal Biochem 1966;15:45-52.

${ }^{8}$ James K, Johnson G, Fudenberg HH. The quantitative estimation of $\alpha_{2}$-macroglobulin in normal, pathological and cord sera. Clin Chim Acta 1966;14:207-14.

${ }^{9}$ Borsey DQ, Fraser DM, Gray RS, Elton RA, Smith AF, Clarke BF. Glycosylated haemoglobin and its temporal relationship to plasma glucose in non-insulin dependent (Type 2) diabetes mellitus. Metabolism 1982;31:362-6.

${ }^{10}$ Hope W, Chesterman CN, Dusting GJ, Smith I, Morgan FJ, Martin TJ. Inhibition by $\beta$-thromboglobulin of prostacyclin $\left(\mathrm{PGI}_{2}\right)$ formation in arterial endothelial cells. Thromb Haemost $1979 ; 42: 8$.

" Van Creveld S, Paulssen MMP. Significance of clotting factors in blood-platelets in normal and pathological conditions. Lancet $1951 ;$ ii:242-4.

${ }^{12}$ Niewiarowski S, Lipinski B, Farbiszewski R, Poplowski A. The release of platelet factor 4 during platelet aggregation and the possible significance of this reaction in haemostasis. Experientia $1968 ; 24: 343-4$.

${ }^{13}$ Dawes J, Smith RC, Pepper DS. The release, distribution and clearance of human B-thromboglobulin and platelet factor 4 . Thromb Res 1978;12:851-61.

${ }^{14}$ Kurihara $Y$, Nakayama $H$, Nakagawa S. Plasma $\beta$-thromboglobulin and platelet factor 4 in renal insufficiency. Throm Res 1980;18:557-60.

${ }^{15}$ Betteridge DJ, Zahavi J, Jones NAG, Shine B, Kakkar VV, Galton DJ. Platelet function in diabetes mellitus in relationship to complications, glycosylated haemoglobin and serum lipoproteins. Eur J Clin Invest 1981;11:273-7.

${ }^{16}$ Campbell IW, Dawes J, Fraser DM, et al. Plasma $\beta$-thromboglobulin in diabetes mellitus. Diabetologia 1977;26:1175-7.

${ }^{17}$ Kazmier FJ, Bowie EJ, O'Fallon WM, Zimmerman BR, Osmundson PJ, Palumbo PJ. A prospective study of peripheral occlusive arterial disease in diabetes IV: Platelet and plasma functions. Mayo Clin Proc 1981;56:243-53.

${ }^{18}$ Preston FE, Ward JD, Marcola BH, Porter NR, Timperley WR, O'Malley BC. Elevated $\beta$-thromboglobulin levels and circulat- 
ing platelet aggregates in diabetic microangiopathy. Lancet 1978;1:238-9.

${ }^{19}$ Burrows AW, Chavin SI, Hockaday TDR. Plasmathromboglobulin concentrations in diabetes mellitus. Lancet 1978;1:235-7.

${ }^{20}$ Rasi V, Ikkala E, Hekali R, Myllyla G. Factors affecting plasma $\beta$-thromboglobulin in diabetes mellitus. Med Biol 1980;58:269-72.

${ }^{21}$ Burrows AW. Beta-thromboglobulin in diabetes: relationships with blood glucose and fibrinopeptide A. Horm Metab Res 1981; suppl II: 22-5.

${ }^{22}$ Corbella E, Miragliotta G, Masperi R, Villa S, Bini A, de Gaetano G, Chiumello G. Platelet aggregation and antithrombin III levels in diabetic children. Haemostasis 1979;8:30-7.

${ }^{23}$ Chimielewski J, Farbiszewski R. Platelet factor 4 (PF4) release during human platelet aggregation in diabetic patients. Thromb Diath Haemorrh 1970;24:203-5.

${ }^{24}$ Nossel HL, Ti M, Kaplan KL, Spanondis K, Soland T, Butler VP. The generation of fibrinopeptide $\mathbf{A}$ in clinical blood samples: evidence for thrombin activity.J Clin Invest 1976;58:1136-44.

${ }^{25}$ Prowse CV, Vigano S, Borsey DQ, Dawes J. The release of beta-thromboglobulin from platelets during the clotting of whole blood. Thromb Res 1980;17:433-42.

${ }^{26}$ Hoare EM, Barnes AJ, Dormandy JA. Abnormal blood viscosity in diabetes mellitus and retinopathy. Biorheology 1976;13:21-5.

${ }^{27}$ Solum NO, Stormorken H. Influence of fibrinogen on the aggregation of washed human blood platelets induced by adenosine diphosphate, thrombin, collagen and adrenaline. Scand J Clin Lab Invest 1965;17 (suppl 84): 170-82.

${ }^{28}$ Mayne JM, Bridges JM, Weaver JA. Platelet, plasma fibrinogen and factor VIII levels in diabetes mellitus. Diabetologia 1970;6:436-40.

${ }^{29}$ Fuller H, Keen JH, Jarrett RJ, et al. Haemostatic variables associated with diabetes and its complications. $\mathrm{Br} \mathrm{Med} J$ 1978;ii:964-6.

${ }^{30}$ Cederholm-Williams SA, Dornan TL, Turner RC. The metabolism of fibrinogen and plasminogen related to diabetic retinopathy in man. Eur J Clin Invest 1981;11:133-8.

${ }^{31}$ Almer LA, Pandolfi M. Fibrinolysis and diabetic retinopathy. Diabetes 1976;25 (suppl 2): 807-9.

32 Jonsson A, Wales ZK. Blood glycoprotein levels in diabetes mellitus. Diabetologia 1976;12:245-50.

${ }^{33}$ Coller BS, Frank RN, Milton RC, Gralnick HR. Plasma cofactors of platelet function: correlation with diabetic retinopathy and haemoglobins Ala-c. Ann Intern Med 1978;88:311-6.

${ }^{34}$ Marciniak E, Farley CH, DeSimone PA. Familial thrombosis due to antithrombin III deficiency. Blood 1974;43:219-31.

${ }^{35}$ Banerjee RN, Sahni AL, Kumere U, Arza N. Antithrombin III deficiency in maturity onset diabetes mellitus and atherosclerosis. Thromb Diath Haemorrh 1974;31:339-45.
${ }^{36}$ Monnier L, Follea G, Mirouze J. Antithrombin III deficiency in diabetes mellitus: influence on vascular degenerative complications. Horm Metab Res 1978;10:470-3.

${ }^{37}$ Sowers JR, Tuck ML, Sowers DK. Plasma antithrombin III and thrombin generation time: correlation with haemoglobin $\mathbf{A}_{1}$ and fasting serum glucose in young diabetic women. Diabetes Care 1980;3:655-8.

${ }^{38}$ Zucker ML, Gomperts ED, Russel D, et al. Antithrombin functional activity after saturated and unsaturated fatty meals and fasting in normal subjects and some disease states. Thromb Res 1979;15:37-48.

${ }^{39}$ Gandolfo GM, DeAngelis A, Torresi MV. Determination of antithrombin III activities by different methods in diabetic patients. Haemostasis 1980;9:15-9.

${ }^{40}$ Elder GE, Mayne EE, Daly JG, Kennedy AL, et al. Antithrombin III activity and other coagulation changes in proliferative diabetic retinopathy. Haemostasis 1980;9:288-96.

4 Calvalho A, Ellman L. Activation of the coagulation system in polycythemia vera. Blood 1976;47:669-78.

42 Ganrot PO, Gydell K, Ekelund $H$. Serum concentration of alpha $_{2}$-macroglobulin, haptoglobin and alpha $_{2}$-antitrypsin in diabetes mellitus. Acta Endocrinol 1967;55:537-44.

${ }^{43}$ James K, Merriman J, Gray RS, Duncan LJP, Herd R. Serum $\alpha_{2}$-macroglobulin levels in diabetes. $J$ Clin Pathol 1980;33:163-6.

${ }^{4}$ Ganrot PO, Schersten B. Serum $\alpha_{2}$-macroglobulin concentration and its variation with age and sex. Clin Chim Acta 1967;15:113-20.

${ }^{45}$ Gray RS, James K, Merriman J et al. Alpha ${ }_{2}$-macroglobulin and proliferative retinopathy in Types I Diabetes. Horm Metab Res 1982;14:389-92.

46 Jaffe EA, Deykin D, Salzman E, Schnippe L. Endothelial cells and biology of Factor VIII. N Engl J Med 1977;296:377-83.

47 Von Willebrand's disease (Editorial). Br Med J 1976;ii:715-6.

${ }^{48}$ Pandolfi M, Almer LO, Holmberg L. Increased von Willebrand-antihaemophilic factor $\mathbf{A}$ in diabetic retinopathy. Acta Ophthalmol 1974;52:823-8.

${ }^{49}$ Gensini GF, Abbate R, Favilla S, Neri Serneri GG. Changes of platelet function and blood clotting in diabetes mellitus. Thromb Haemost 1979;42:983-93.

${ }^{\text {so }}$ Boneu B, Abbal M, Plante J, Bierme R. Factor VIII complex and endothelium damage. Lancet $1975 ; \mathrm{i}: 1430$.

s1 Giustolisi R, Musso R, Russo M, Cantania N, Lombardo T, Cacciola E. Possible evidence for increased Factor VIII antigen synthesis in vascular endothelium of diabetic subjects. Thromb Haemost 1982;47:293.

52 Lufkin EG, Fass DN, O'Fallon WM, Bowie EJW. Increased von Willebrand factor in diabetes mellitus. Metabolism 1979;28:63-6.

Requests for reprints to: Dr DQ Borsey, Ninewells Hospital, Ninewells, Dundee DD1 9SY, Scotland. 